\title{
Why Climate Change Matters in Healthcare: The Need to Advocate for Our Planet
}

\author{
Nathan Chiarlitti* \\ Faculty of Medicine, University of Ottawa, Ontario, Canada
}

\section{COMMENTARY}

It's easy to feel unaware or disconnected to climate change in our Canadian society. Wildfires in Australia (2020) and California (2018) or floods in Indonesia $(2019,2020)$ and India (2017-2020) seem far from our borders and often slip into our unconscious after occupying short segments on the evening news. Most of our parents were born in an era where recycling and composting were minimally encouraged, o-zone damage was unexplored, and species extinction was largely unheard of. We're now aware that fossil fuel consumption is bad for the environment, but the connection to our personal lives and the downstream effects it has on our healthcare system is less intuitive. With patient's health and our future quality of life inevitably connected to climate change, having an awareness of our current actions and the consequences of our past actions is paramount.

There is a clear correlation between carbon dioxide emissions and global temperatures, so much so that the two graphs can be nearly superimposed [1,2]. Plants sequester the carbon in our atmosphere and convert it to oxygen; however, they also act as major carbon reserves [3]. As temperatures rise due to fossil fuel consumption, wildfires become more common, and when trees are burned, they release the carbon they have stored into the atmosphere [4]. For perspective, the California wildfires in 2020 released nearly the same amount of carbon as the entire Canadian transportation subsector of passenger motorcycles, buses, trains, and domestic aviation in 2018 (roughly 100 million tonnes) [5]. Similar to plants, artic ice acts as a carbon reserve and releases methane (which is 84 times more potent than carbon dioxide) when it melts [4]. In essence, a dangerous positive feedback loop is taking place every second of every day; the increasing global temperature leads to more wildfires and the melting of artic ice- both of which release massive amounts of greenhouse gasses, further warming the planet.
Rising global temperatures pose many problems. The most intuitive sequalae is an increased frequency of heatwaves which discriminately effect the elderly, individuals with comorbidities, and those with low socioeconomic status [6]. For example, in Montreal, 66 people (2/3 seniors) died as a result of a 2018 heat wave [7]. It is also well documented that heat produces an increase in aggression, anti-social behavior and suicidality [4,8]. With rising mental health illnesses being diagnosed and managed in Canada, the correlation with elevated environmental temperature is an important connection that must be recognized and addressed.

A warming planet is only one component of climate change. An additional repercussion of fossil fuel use is the increased production of particulate matter $[2,4]$ which negatively affects air quality. Poor air quality leads to an increase in respiratory illnesses and exacerbations of other health conditions such as lung cancer, cardiovascular disease and pre-natal health [2,4,9-11]. Globally, the World Health Organization estimates around 7 million people die each year due to polluted air exposure [10]. In Canada, polluted air is estimated to cost the healthcare system over $\$ 110$ billion annually [11].

Heat waves and air pollution may be intuitive consequences of climate change; however, other downstream affects aren't as obvious. As atmospheric carbon dioxide levels rise, plants make more sugar and less nutrients namely protein, iron, calcium, Vitamin C [4]. With increasing global levels of obesity, diabetes, and cardiovascular disease, we must consider that less nutritious food consumption can augment pre-existing metabolic conditions $[12,13]$. Other climate change sequalae include altering vector patterns, marine ecosystem destruction and increasing sea levels which affect public health and healthcare systems locally and globally $[2,4]$.

\begin{tabular}{|c|c|}
\hline & $\begin{array}{l}\text { Address for correspondence: Nathan Chiarlitti, MD Faculty of Medicine, University } \\
\text { of Ottawa, Ontario, Canada }\end{array}$ \\
\hline & $\begin{array}{l}\text { Received: November 03, } 2021 \quad \text { Published: November 10, } 2021 \\
\text { How to cite this article: Nathan Chiarlitti. Why Climate Change Matters in Healthcare: The Need } \\
\text { to Advocate for Our Planet. 2021- 3(6) OAJBS.ID.000344. DOI: } 10.38125 / O A J B S .000344\end{array}$ \\
\hline
\end{tabular}


The effects of climate change in Canada may still seem insidious and incognito compared to other parts of the world; however, the following clinical examples can illustrate the implications climate change has and will have on health, magnifying its urgency. What does an increase in temperature mean for patients with a mental health illness who may be more prone to aggression? What does the increase in air particulate matter mean to a 4-year-old with asthma or an 80-year-old with COPD? What does reduce plant macronutrients and increased sugars mean for people with type 2 diabetes or the patient with heart disease and hypertension?

The call to act as a medical community has never been more urgent. Our next ten years will likely dictate the severity of our current climate crisis [14]. The CMA has taken a stand against climate change, first by divesting in companies that primarily rely on fossil fuels (2015), and by consistently bringing the issue forward in federal elections and policy briefs $[15,16]$. Although this is encouraging, there is still much we can do in our personal lives to mitigate our carbon footprint, such as reducing our consumption of plastics. In Canada, a disturbingly low amount (9\%) of plastic is recycled, leaving most to find their way to landfills or natural environments [17]. Alarmingly, the healthcare industry is a major source of plastic consumption and single-use plastic waste (even prior to COVID-19) [18]. Some hospitals and healthcare centers in the US and UK have begun composting, implementing renewable energy at their facilities, and targeting efficiencies in daily activities to reduce waste and limit their carbon footprints [18]. As healthcare professionals and community leaders, making pledges to strive to be both individually and unitedly carbon neutral, and continuing to advocate for sustainable living will help to continually bring climate change to the forefront.

Finally, healthcare workers can initiate conversations more ubiquitously about climate change awareness and methods to reduce carbon footprints in the clinical setting. Emphasizing simple techniques like shopping locally for produce (as to reduce transit time and increase available nutrients), participating in active transportation, composting food scraps, and limiting meat consumption could result in large carbon footprint reductions $[4,19]$. The decision to act as a medical community should not only be out of feelings of necessity for distant communities stricken by natural disasters. Our action should also be motivated by what our inaction will do to the people we care about and care for in our local communities.

\section{REFERENCES}

1. Scheffer M, Brovkin V, Cox PM (2006) Positive feedback between global warming and atmospheric $\mathrm{CO}_{2}$ concentration inferred from past climate change. Geophysical research letters, Vol. 33(10).

2. Lemery J, Auerbach P (2017) Enviromedics: The impact of climate change on human health. Rowman \& Littlefield, USA.

3. Rajeew K, Sharad P, Apurv P (2006) Plant roots and carbon sequestration. Current Science, pp. 885-890.

4. Wallace-Wells D (2020) The uninhabitable earth: Life after warming. Tim Duggan Books.

5. Greenhouse Gas Emissions (2020) Government of Canada.

6. Campbell S, Remenyi TA, White CJ, Johnston FH (2018) Heatwave and health impact research: A global review. Health \& Place 53: 210-218.

7. Montreal heat waves may have claimed 14 lives this year, public health says. (July 2020). CBC News.

8. Miles-Novelo A, Anderson CA (2019) Climate change and psychology: Effects of rapid global warming on violence and aggression. Current Climate Change Reports 5(1): 36-46.

9. Jiang XQ, Mei XD, Feng D (2016) Air pollution and chronic airway diseases: what should people know and do? Journal of Thoracic Disease 8(1): E31-E40.

10. Ambient Air Pollution: A Global Assessment of Exposure and Burden of Disease (2016). WHO.

11. Health Effects of Air Pollution (2020) Health Canada.

12. Lutsey PL, Lyn MS, June S (2008) Dietary intake and the development of the metabolic syndrome: the atherosclerosis risk in communities' study. Circulation 117(6): 754-761.

13. Grundy SM (2016) Metabolic syndrome update. Trends in Cardiovascular Medicine 26(4): 364-373.

14. Masson-Delmotte V, Zhai P, Pörtner HO, Roberts D, Skea J, et al. (2018) Summary for Policymakers. In: Global Warming of $1.5^{\circ} \mathrm{C}$. An IPCC Special Report on the impacts of global warming of $1.5^{\circ} \mathrm{C}$ above pre-industrial levels and related global greenhouse gas emission pathways, in the context of strengthening the global response to the threat of climate change, sustainable development, and efforts to eradicate poverty. World Meteorological Organization, Geneva, Switzerland, pp. 32.

15. Desrosiers PC, Hackett F, McGregor D, Banadiak K (2020) The lancet countdown on health and climate change: Policy brief for Canada.

16. Howard C, Buse C, Rose C, MacNeill A, Parkes M (2019) The lancet countdown on health and climate change: Policy brief for Canada.

17. Canada one-step closer to zero plastic waste by 2030 (2020) Environment and climate change Canada.

18. Ngo Hope (2020) How do you fix healthcare's medical waste problem? BBC Future Planet.

19. Godfray HCJ, Aveyard P, Garnett T, Hall JW, Key TJ, et al. (2018) Meat consumption, health, and the environment. Science 361(6399): eaam5324. 